\title{
Substance P Recognition by a Subset of Human T Lymphocytes
}

D. G. Payan, D. R. Brewster, A. Missirian-Bastian, and E. J. Goetzl

Howard Hughes Medical Institute Laboratories

and the Department of Medicine, University of California

Medical Center, San Francisco, California 94143

bstract. The interaction of substance $P$ with human blood T-lymphocytes, which stimulates T-lymphocyte proliferation, was quantified by both flow cytometric and direct binding assays. Fluorescencedetection flow cytometry recorded the binding of dichlorotriazinylamino-fluorescein-labeled substance $\mathbf{P}$ to $21 \pm 10 \%($ mean $\pm S D, n=6)$ and $35 \pm 8 \%(n=2)$ of human blood T-lymphocytes before and after stimulation with $10 \mu \mathrm{g} / \mathrm{ml}$ of phytohemagglutinin, respectively. The suppressor-cytotoxic (leu 2a) and helper-inducer (leu 3a) subsets identified by phycoerythrin-labeled monoclonal antibodies contained substance P-reactive T-lymphocytes at respective mean frequencies of 10 and $18 \%$. $\left[{ }^{3} \mathrm{H}\right]$ substance $P$ bound rapidly and reversibly to a mean of $7035 \pm 2850$ sites/T-lymphocyte, which exhibited a dissociation constant $\left(K_{\mathrm{D}}\right)$ of $1.85 \pm 0.70 \times 10^{-7} \mathrm{M}$ (mean $\pm \mathrm{SD}, n=5$ ). [D-Pro ${ }^{2}, \mathrm{D}-\mathrm{Phe}^{7}, \mathrm{D}-\mathrm{Trp}^{9}$ ] substance P inhibited the binding of dichlorotriazinylamino-fluorescein-labeled substance $P$ and $\left[{ }^{3} \mathrm{H}\right]$ substance $P$ to T-lymphocytes at concentrations that suppressed the proliferative response to substance $P$. Substance $P$ (4-11), eledoisin, and substance $\mathrm{K}$ ( $\alpha$-neurokinin), which all share with substance $P$ the carboxy-terminal substituent -Gly-Leu-Met- $\mathrm{NH}_{2}$, were more potent than substance $P$ (1-4) in inhibiting the binding of $\left[{ }^{3} \mathrm{H}\right]$ substance $P$ to $\mathrm{T}$ lymphocytes, suggesting the importance of this sequence in the interaction. Purified human blood B-lymphocytes, monocytes, polymorphonuclear leukocytes, and platelets, and cultured Hut 78 cutaneous lymphoma T-cells, Jurkat cells, Molt-4 lymphoblasts, and HL-60 and U-937 monocyte-like cells all showed only minimal specific binding of $\left[{ }^{3} \mathrm{H}\right]$ substance $P$. The recognition of substance

Received for publication 11 November 1983 and in revised form 31 May 1984

J. Clin. Invest.

(c) The American Society for Clinical Investigation, Inc. $0021-9738 / 84 / 10 / 1532 / 08 \$ \$ 1.00$

Volume 74, October 1984, 1532-1539
P by T-lymphocytes provides one mechanism for selective modulation of immunity by sensory nerves.

\section{Introduction}

Modulation of immunologic responses by elements of the central and peripheral nervous system appears to be attributable in part to the bidirectional effects of neuropeptides on distinct functions of lymphocytes. The results of in vitro studies of lymphocyte proliferation have shown that the responses to mitogens are suppressed by somatostatin $(1,2)$ and enhanced by substance $P(S P)^{1}(3)$ and $\beta$-endorphin (4). That different aspects of neuropeptide structure determine specifically the net effect on other lymphocyte functions was suggested by the capacity of $\alpha$-endorphin but not $\beta$-endorphin to inhibit Tlymphocyte-dependent antibody production (5), and of methionine-enkephalin and $\beta$-endorphin but not morphine or $\alpha$ endorphin to enhance the natural killer activity of lymphocytes (6). The interactions of neuropeptides with lymphocytes have been defined by direct analyses of the binding of methionineenkephalin to T-lymphocytes (7) and of vasoactive intestinal polypeptide to both Molt-4 lymphoblasts and T-lymphocytes $(8,9)$.

SP is an undecapeptide of amino acid sequence Arg-ProLys-Pro-Gln-Gln-Phe-Phe-Gly-Leu-Met- $\mathrm{NH}_{2}$, which has been identified in the central and peripheral nervous system and intestinal tract (10-13) and implicated in the mediation of hypersensitivity reactions by the detection of elevated levels of SP in sensory nerves supplying localized sites of chronic inflammation $(14,15)$. SP elicits or enhances functional responses of human mast cells, polymorphonuclear (PMN) leukocytes, T-lymphocytes, and guinea pig peritoneal macrophages at concentrations ranging from $10^{-11}$ to $10^{-5} \mathrm{M}(3,16-$ 19). Furthermore, the stimulation of $T$-lymphocyte proliferation by SP was inhibited specifically by the otherwise immunologically inactive analogue $\left[D-\operatorname{Pro}^{2}, D_{-} \operatorname{Phe}^{7}, D_{-} \operatorname{Trp}^{9}\right] \operatorname{SP}(3,20)$. The

1. Abbreviations used in this paper: DTAF, dichlorotriazinylamino fluorescein; FACS, fluorescence-activated cell sorter; $\mathrm{LTB}_{\mathbf{4}}$, leukotriene $B_{4}$; M199-HPS and RPMI-HPS, medium 199 containing Hepes (25 $\mathrm{mM}$, pH 7.4), penicillin (100 U/ml), and streptomycin $(100 \mu \mathrm{g} / \mathrm{ml})$; PE, phycoerythrin; PHA, phytohemagglutin-M; SP, substance P; SP*, substance $P$ coupled to DTAF. 
preparation and purification of fluorescein-labeled substance $P$ (SP*) now has permitted an evaluation by fluorescencedetection flow cytometry of the recognition of SP by a small subset of human blood T-lymphocytes, which manifest a specificity for $\mathrm{SP}^{*}$ and $\left[{ }^{3} \mathrm{H}\right] \mathrm{SP}$ similar to that observed initially in studies of the effects of SP on T-lymphocyte function (3). Furthermore, the concurrent application of SP* and of phycoerythrin-labeled monoclonal antibodies specific for antigenic determinants on functionally distinct subsets of T-lymphocytes now indicate that the SP* reactive T-lymphocytes are distributed in both the suppressor-cytotoxic and helper-inducer subsets.

\section{Methods}

Medium 199, RPMI-1640, sheep erythrocytes (Microbiological Associates Bioproducts, Walkersville, MD), $6 \mathrm{~g} \%$ macromolecular dextran70 in $0.15 \mathrm{M}$ saline (Macrodex), Ficoll-Hypaque (Pharmacia Fine Chemicals, Inc., Piscataway, NJ), 4-(2-hydroxy-ethyl)-1-piperazine ethanesulfonic acid (Hepes), penicillin $(1,000 \mathrm{U} / \mathrm{ml})$, streptomycin $(1,000$ $\mu \mathrm{g} / \mathrm{ml}$; Gibco Laboratories, Grand Island, NY), phytohemagglutin-M (PHA) (Difco Laboratories, Inc., Detroit, MI), $\boldsymbol{n}$-butyl phthalate (Fisher Scientific Co., Pittsburgh, PA), dinonyl phthalate (ICN Pharmaceuticals, Inc., Plainview, NY), synthetic SP, SP (1-4), SP (4-11), eledoisin, $\alpha$ neurokinin (substance K), [D-Pro $\left.{ }^{2}, \mathrm{D}-\mathrm{Phe}^{7}, \mathrm{D}-\mathrm{Trp}^{9}\right] \mathrm{SP}$, somatostatin (1-14) (Peninsula Laboratories, Inc., Belmont, CA), $\left.{ }^{3} \mathrm{H}\right] \mathrm{SP}(25-55 \mathrm{Ci} /$ mmol) (New England Nuclear, Boston, MA), $1.5 \mathrm{ml}$ conical polypropylene tubes (Sarstedt, Inc., Princeton, NJ), silica gel $\mathrm{H}$ of $250 \mu \mathrm{m}$ thickness on $20 \times 20-\mathrm{cm}$ plates (Analtech, Inc., Newark, DE), phycoerythrin (PE)-conjugated monoclonal mouse antibodies to leu-3a and leu-2a (Becton-Dickinson, Inc., Mountainview, CA), dichlorotriazinylaminofluorescein (DTAF) (Research Organics, Inc., Cleveland $\mathrm{OH}$ ), organic solvents which had been redistilled from glass (Burdick and Jackson Laboratories, Inc., Muskegon, MI), reagents for determining the amino acid composition of polypeptides (Beckman Instruments, Inc., Palo Alto, CA, and Pierce Chemical Co., Rockford, IL), human promyelocytic leukemia HL-60 and Jurkat cells (Dr. J. Stobo, University of California at San Francisco), cultures of Molt-4 lymphoblasts, U937 monocyte-like cells, Hut 78 T-cells (American Type Culture Collection, Rockville, MD), and 1,25-dihydroxy vitamin $\mathrm{D}_{3}$ $\left[1,25(\mathrm{OH})_{2} \mathrm{D}_{3}\right]$ (Hoffman-La Roche, Nutley, NJ) were obtained from the designated suppliers.

Isolation of human T- and B-lymphocytes, PMN leukocytes, monocytes, and platelets. Mixed leukocytes from heparin-anti-coagulated blood of normal subjects were centrifuged on Ficoll-Hypaque cushions to resolve mononuclear leukocytes from PMN leukocytes. The PMN leukocytes in the pellet were resuspended in $1 \mathrm{ml}$ of AB-positive human serum that was diluted to $10 \mathrm{ml}$ with distilled water at room temperature to lyse contaminating erythrocytes. After $20 \mathrm{sec}, \mathbf{4 0} \mathrm{ml}$ of Medium 199 containing $25 \mathrm{mM}$ Hepes (pH 7.4), $100 \mathrm{U} / \mathrm{ml}$ of penicillin, and $100 \mu \mathrm{g} / \mathrm{ml}$ of streptomycin (M199-HPS) was added, and the PMN leukocytes were recovered by centrifugation and washed twice with M199-HPS; the purity of the PMN leukocytes was >95\% (21). The mononuclear leukocytes at the buffer and Ficoll-Hypaque interface were washed twice in M199-HPS and then were incubated with neuraminidase-treated fresh sheep erythrocytes to achieve rosetting of the T-lymphocytes (21). The mixtures were centrifuged on FicollHypaque cushions to separate the T-lymphocyte rosettes from less dense nonrosetting monocytes and B-lymphocytes. The erythrocytes were lysed by hypotonic exposure, and the T-lymphocytes were washed and resuspended in M199-HPS. The purity of the T-lymphocytes was $>95 \%$, with $<3 \%$ monocytes detected by a nonspecific esterase stain, and T-lymphocyte viability was always $>\mathbf{9 7 \%}$, as determined by the exclusion of trypan blue dye (21).

The nonrosetting mixture of monocytes and B-lymphocytes was resuspended at a concentration of $1 \times 10^{6} / \mathrm{ml}$ of M199-HPS with $10 \%$ (vol:vol) human AB serum and incubated in $75 \mathrm{~cm}^{2}$ plastic tissue culture flasks for $1 \mathrm{~h}$ at $37^{\circ} \mathrm{C}$ in $5 \% \mathrm{CO}_{2}: 95 \%$ air to remove the adherent monocytes. The contents of the flasks were decanted; the nonadherent B-lymphocytes were washed and resuspended in M199HPS and the incubation in plastic flasks repeated to remove residual adherent monocytes. The purity of the B-lymphocytes always was $>90 \%$, with $<5 \%$ T-lymphocytes and $8 \%$ monocytes; B-lymphocyte viability was $>94 \%$, as determined by the exclusion of trypan blue dye (21). Monocytes were obtained by scraping the plastic $75 \mathrm{~cm}^{2}$ flasks with a rubber spatula and washing the detached cells in M199-HPS. The purity of the monocytes was always $>85 \%$ as assessed by a nonspecific esterase stain, and monocyte viability was always $>90 \%$.

Human platelets from normal subjects who had not taken aspirin or other platelet-active medication for at least $7 \mathrm{~d}$ were isolated from citrate-anticoagulated venous blood and washed three times on cushions of autologous erythrocytes, as described (22). The washed platelets were freed of erythrocytes by centrifugation at $10 \mathrm{~g}$ for $5 \mathrm{~min}$ and were resuspended in M199-HPS (pH 7.4) containing 0.1\% (wt:vol) human serum albumin.

Maintenance of Molt-4, U-937, Hut 78, Jurkat, and HL-60 cell cultures. Cells were cultured at a density of $\sim 5 \times 10^{5} / \mathrm{ml}$ in $75 \mathrm{~cm}^{2}$ plastic flasks in RPMI-1640 with L-glutamine, 15\% (vol:vol) heatinactivated fetal-calf serum, $25 \mathrm{mM}$ Hepes (pH 7.4), penicillin (100 $\mathrm{U} / \mathrm{ml}$ ), and streptomycin $(100 \mu \mathrm{g} / \mathrm{ml})(\mathrm{RPMI}-\mathrm{HPS})$ at $37^{\circ} \mathrm{C}$ in $5 \%$ $\mathrm{CO}_{2}: 95 \%$ air. The cultures were divided every $48-72 \mathrm{~h}$ and the cells used within $2 \mathrm{~d}$ of a subdivision. The cells were washed twice and resuspended in M199-HPS; viability was always $>95 \%$, as determined by the exclusion of trypan blue dye (21).

T-lymphocytes were cultured in RPMI-HPS for $48 \mathrm{~h}$ with and without $10 \mu \mathrm{g} / \mathrm{ml}$ of PHA and the degree of proliferation was quantified with a $0.2 \mathrm{ml}$ portion of each suspension. The T-lymphocytes were diluted to $1 \times 10^{6} / \mathrm{ml}$ and transferred to wells of microtiter plates containing $1 \mu \mathrm{Ci}$ of $\left[{ }^{3} \mathrm{H}\right]$ thymidine (New England Nuclear) and the incubation continued for $8 \mathrm{~h}$ at $37^{\circ} \mathrm{C}$ in $5 \% \mathrm{CO}_{2}: 95 \%$ air. The uptake of $\left[{ }^{3} \mathrm{H}\right]$ thymidine was quantified by trapping and washing the $T$ lymphocytes on glass fiber filters in a PHD cell harvester (Cambridge Technology, Inc., Cambridge, MA), and then counting the radioactivity as described (23). In two separate experiments, the uptake of $\left[{ }^{3} \mathrm{H}\right]$ thymidine by the unstimulated T-lymphocytes was $253 \pm 67$ $\mathrm{cpm}($ mean $\pm \mathrm{SD})$ and by the PHA-stimulated T-lymphocytes was $17,641 \pm 2345 \mathrm{cpm}$

Induction of differentiation of $U-937$ and $H L-60$ cells by $1,25(\mathrm{OH})_{2} \mathrm{D}_{3}$. U-937 and HL-60 cells were stimulated to differentiate into monocyte-like cells by $1,25(\mathrm{OH})_{2} \mathrm{D}_{3}$ as described $(24,25)$ by incubation of suspensions of $5 \times 10^{5} / \mathrm{ml}$ of RPMI-HPS in $75 \mathrm{~cm}^{2}$ tissue culture flasks with $10^{-7} \mathrm{M} 1,25(\mathrm{OH})_{2} \mathrm{D}_{3}$ at $37^{\circ} \mathrm{C}$ in $5 \% \mathrm{CO}_{2}: 95 \%$ air for $72 \mathrm{~h}$. The contents of the flasks were decanted and the adherent differentiated cells removed with a rubber spatula were washed and resuspended in M199-HPS; viability of the adherent differentiated cells always exceeded $85 \%$, as assessed by the exclusion of trypan blue. In two successive experiments, the extent of differentiation into monocytes was $65 \pm 10 \%$ (mean \pm SD) and $80 \pm 5 \%$ for the HL-60 and U-937 cells, respectively, as assessed by the increased percentage of adherent cells and the percentage which expressed nonspecific esterase activity (25). 
Preparation of DTAF-SP (SP*). To prepare fluorescent SP, 2.5$5.0 \mathrm{mg}$ of DTAF and $0.5-1.0 \mathrm{mg}$ of SP were reacted in $0.4-0.8 \mathrm{ml}$ of $0.2 \mathrm{M}$ sodium carbonate-buffered $0.15 \mathrm{M} \mathrm{NaCl}(\mathrm{pH} \mathrm{9.0)}$ for $2 \mathrm{~h}$ at $37^{\circ} \mathrm{C}$. The mixture was applied to one end of a $20 \times 20-\mathrm{cm}$ plate of $250 \mu \mathrm{m}$ thick silica gel $\mathrm{H}$ that was developed in a sealed chamber with chloroform:methanol:glacial acetic acid (15:5:1, vol:vol:vol). Unreacted DTAF and SP, which were detected by ultraviolet light-induced fluorescence and ninhydrin staining, respectively, migrated as separate spots with $R_{F}$ values of 0.91 and 0.05 , respectively. SP coupled to DTAF (SP*) migrated as a single spot with an $\mathbf{R}_{\mathbf{F}}$ of 0.23 . The SP*. containing silica gel was scraped from the plate and eluted with four portions of $1 \mathrm{ml}$ of methanol. The eluate then was dried with a continuous stream of $\mathrm{N}_{2}$ and resuspended in $0.4-0.8 \mathrm{ml}$ of M199HPS. To verify the amino acid composition of the SP*, replicate portions were lyophilized in $9 \times 150$-mm glass test tubes, resuspended in $0.3 \mathrm{ml}$ of constant boiling $(5.7 \mathrm{M}) \mathrm{HCl}$, and hydrolyzed as described (26). The amino acids were quantified with a Durrum D500 analyzer, utilizing norleucine as an internal standard (Dionex Co., Sunnyvale, CA) (26). For two different preparations, the relative amino acid composition of the SP* was Lys 0.91 (1), Arg 0.99 (1), Gln 1.93 (2), Pro 2.11 (2), Gly 0.94 (1), Met 0.97 (1), Leu 1.02 (1), and Phe 2.2 (2), as compared with that expected for the sequence Arg-Pro-Lys-ProGln-Gln-Phe-Phe-Gly-Leu-Met-NH $\mathrm{N}_{2}$ and indicated in the parentheses after each value.

Assessment of the interaction of SP-DTAF (SP*) with T-lymphocytes and other cells. In each experiment, $1 \times 10^{7} \mathrm{~T}$-lymphocytes, monocytes, PMN leukocytes, or cultured cells in $0.2 \mathrm{ml} \mathrm{M199-HPS}$ were incubated for $40 \mathrm{~min}$ at $4^{\circ} \mathrm{C}$ with $1-3 \times 10^{-7} \mathrm{M} \mathrm{SP}$ or unconjugated DTAF. The labeled T-lymphocytes were washed and resuspended in $1 \mathrm{ml}$ of M199-HPS at $4^{\circ} \mathrm{C}$ immediately before introduction into a BectonDickinson fluorescence-activated cell sorter (FACS IV) equipped with a $2 \mathrm{~W}$ Argon laser (Spectra Physics, Mountainview, CA) operating at $400 \mathrm{~mW}$ that excited at $488 \mathrm{~nm}$. The emitted light was passed through a long-pass filter and analyzed at $515 \mathrm{~nm}$. Fluorescence intensity was measured on a scale of logarithmic amplitude which was calibrated so that a change of 57 channels was the equivalent of a 10-fold increase in fluorescence intensity. For each measurement of fluorescence, 2 $\times 10^{5} \mathrm{~T}$-lymphocytes were counted. The interaction of $\mathrm{SP}^{*}$ with the T-lymphocytes was analyzed in terms of either two parameters (relative cell number, and relative fluorescence intensity) or three parameters (forward light scatter, relative cell number, and relative fluorescence intensity).

The interaction of SP with a specific subset of T-lymphocytes was quantified by dual color FACS analysis after sequential exposure of mixed T-lymphocytes to PE-labeled monoclonal leu-3a and leu-2a antibodies, which identify the helper-inducer and suppressor-cytotoxic subsets, respectively, and to SP coupled to DTAF (SP*). $1 \times 10^{7} \mathrm{~T}$ lymphocytes in $0.2 \mathrm{ml}$ of M199-HPS were incubated at $4^{\circ} \mathrm{C}$ for 45 min with $0.05 \mathrm{ml}$ of either leu-3a or leu-2a bearing PE. The subsetlabeled T-lymphocytes then were washed once and incubated with SP* as described above. Dual color FACS analysis was carried out with a single $2 \mathrm{~W}$ Argon laser operating at $400 \mathrm{~mW}$. Fluorescein staining was excited at $488 \mathrm{~nm}$ and the emitted light was passed through a longpass filter and analyzed at $515 \mathrm{~nm}$, while PE staining excited at 488 $\mathrm{nm}$ and was analyzed with a $500 \mathrm{~nm}$ beam splitter and two six-cavity band-pass filters (530/30 and 575/25) (Becton Dickinson, Inc.).

Measurement of the binding of $\left[{ }^{3} \mathrm{H}\right]$ substance $P$ to blood $T$ lymphocytes and other cells. In each experiment, a concentration of $\left[{ }^{3} \mathrm{H}\right] \mathrm{SP}$ ranging from 3 to $30 \mathrm{nM}$ without and with different concentrations of SP, [D-Pro ${ }^{2}$, D-Phe ${ }^{7}$, D-Trp] $]$ SP, SP substituent peptides, substance K, eledoisin, or somatostatin was incubated with duplicate suspensions of $1 \times 10^{7} \mathrm{~T}$-lymphocytes or other cells in a final volume of $0.3 \mathrm{ml}$ for $40 \mathrm{~min}$ at $4^{\circ} \mathrm{C}$. The amount of bound radioactivity was determined by sedimenting the T-lymphocytes in each suspension through a $0.3 \mathrm{ml}$ layer of phthalate oils (27) in a $1.5 \mathrm{ml}$ conical polypropylene tube that was centrifuged for $30 \mathrm{~s}$ at $8000 \mathrm{~g}$ in a Beckman microfuge B (Beckman Instruments, Inc.). The tip of the polypropylene tube containing the T-lymphocyte pellet was cut off with a razor blade, and the contents of the tip were resuspended with a pasteur pipette in $3 \mathrm{ml}$ of Hydrofluor for the quantification of radioactivity in the pellet.

The total number of moles of SP bound to the T-lymphocytes was determined by dividing the cpm bound to the cells by the specific activity of $\left[{ }^{3} \mathrm{H}\right] \mathrm{SP}$. The amount of radioactivity bound in the presence of $3.0 \times 10^{-8}$ to $1.0 \times 10^{-4} \mathrm{M}$ nonradioactive SP was divided by the same value for the specific activity of $\left.{ }^{3} \mathrm{H}\right] \mathrm{SP}$ to determine the level of nonspecific binding of SP. The number of moles of SP specifically bound to the T-lymphocytes was calculated by subtracting the nonspecific binding from the total binding.

\section{Results}

Characteristics of the interaction of SP-DTAF (SP*) with human blood T-lymphocytes. T-lymphocytes were labeled with $\mathrm{SP}^{*}$ and the distribution of labeling analyzed with a FACS to assess whether SP is recognized by all of the T-lymphocytes or only a limited subpopulation. The flow cytometric analyses demonstrated a small peak of positively fluorescent cells (Fig. 1 ), which represents the T-lymphocytes that bind $\mathrm{SP}^{*}$. In six consecutive experiments with T-lymphocytes purified from different normal subjects, the number of cells labeled with SP* accounted for $21 \pm 10 \%$ (mean $\pm S D)$ of the total T-lymphocytes. In contrast, DTAF alone failed to reveal a specifically staining population of cells. The specificity of labeling of T-lymphocytes with $\mathrm{SP}^{*}$ was examined using a similar experimental design, but including replicate suspensions incubated with a mixture of SP* and $10^{-5} \mathrm{M}$ [D-Pro $\left.{ }^{2}, \mathrm{D}-\mathrm{Phe}^{7}, \mathrm{D}-\mathrm{Trp}{ }^{9}\right] \mathrm{SP}$, which prevents the enhancement of T-lymphocyte function by SP (3). In the

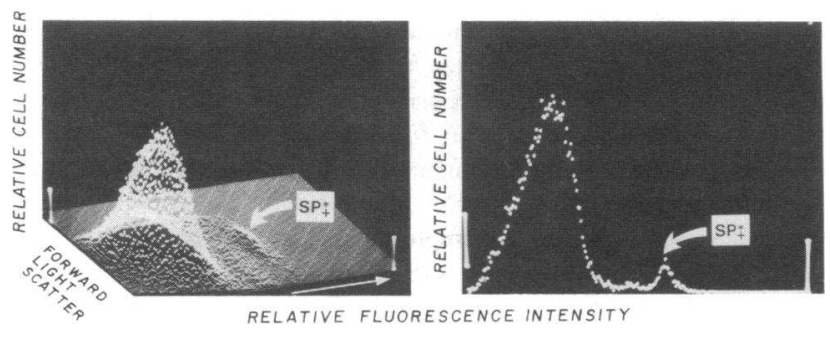

Figure 1. Flow cytometric analysis of the binding of $\mathrm{SP}^{*}$ to human T-lymphocytes. $1 \times 10^{7} \mathrm{~T}$-lymphocytes in $0.2 \mathrm{ml}$ of M199-HPS were incubated for $40 \mathrm{~min}$ at $4^{\circ} \mathrm{C}$ with $1-3 \times 10^{-7} \mathrm{M} \mathrm{SP}$, washed, and analyzed in a FACS IV. Fluorescence intensity is depicted on a log amplitude scale. The subset of T-lymphocytes reactive with SP is designated SP*. 
absence of [D-Pro $\left.{ }^{2}, \mathrm{D}-\mathrm{Phe}^{7}, \mathrm{D}-\mathrm{Trp}^{9}\right] \mathrm{SP}$, a positively fluorescent peak of T-lymphocytes labeled with SP* is detected, representing $15 \%$ of the total T-lymphocytes (Fig. $2 A$ ). The peptide antagonist of the effects of SP on T-lymphocytes eliminated completely any labeling of T-lymphocytes with SP* (Fig. 2 B).

The binding of SP* to T-lymphocytes, which had been stimulated by PHA to proliferate, was evaluated in order to examine the responsiveness of the SP-reactive subset and the effects of expansion of the subset on the specificity of binding of SP. At the end of the period of exposure to PHA, Tlymphocyte viability was $85 \pm 5 \%($ mean $\pm \mathrm{SD}, n=2)$ and $81 \pm 7 \%$ for the unstimulated and PHA-stimulated T-lymphocytes, respectively, as assessed by the exclusion of trypan blue. The labeling of PHA-stimulated T-lymphocytes with SP* increased to $35 \pm 8 \%$ (mean $\pm \mathrm{SD}, n=2$ ), as compared with $23 \pm 6 \%$ for unstimulated T-lymphocytes from the same donors. The binding of SP* by PHA-stimulated T-lymphocytes was reversed completely by $10^{-5} \mathrm{M}$ [D-Pro $\left.{ }^{2}, \mathrm{D}-\mathrm{Phe}^{7}, \mathrm{D}-\mathrm{Trp}^{9}\right] \mathrm{SP}$, as with unstimulated T-lymphocytes. In two consecutive experiments with SP*, PMN leukocytes, monocytes, Molt-4 lymphoblasts, Hut 78 cells, and Jurkat cells failed to develop specific fluorescence, indicating a lack of recognition of SP.

Dual immunofluorescent staining of T-lymphocytes with SP* and subset-specific monoclonal antibodies conjugated with $\mathrm{PE}$ demonstrated $\mathrm{SP}^{*}$-reactive T-lymphocytes in both subsets (Figs. 3 and 4). In the suppressor-cytotoxic subset identified
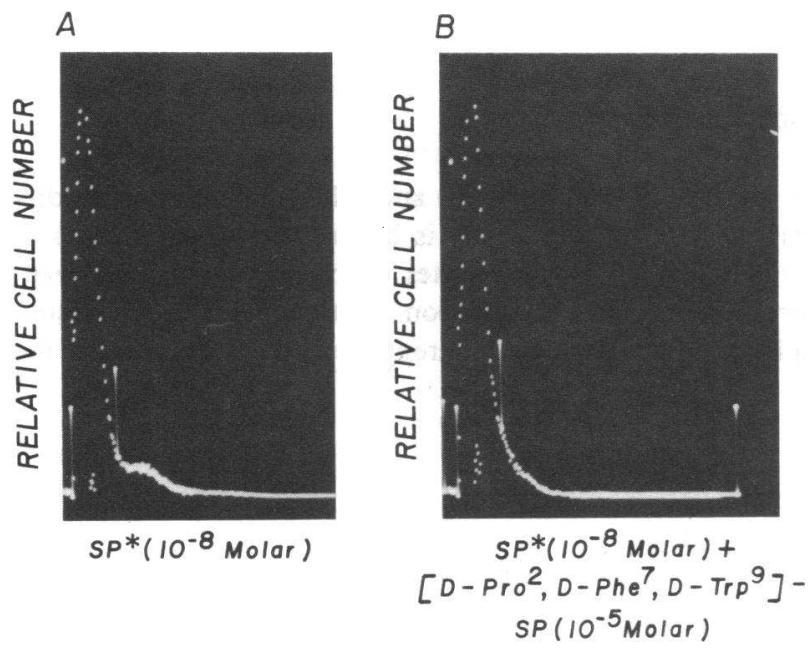

\section{RELATIVE FLUORESCENCE INTENSITY}

Figure 2. Flow cytometric analysis of the specificity of binding of $\mathrm{SP}^{*}$ to human T-lymphocytes. $1 \times 10^{7} \mathrm{~T}$-lymphocytes were incubated with $\mathrm{SP}^{*}$ as described in Fig. 1 . In $(A)$, the binding of $1 \times 10^{-8}$ M SP* was subjected to two parameter analysis; in $(B)$, T-lymphocytes were incubated with both $1 \times 10^{-8} \mathrm{M} \mathrm{SP}^{*}$ and $10^{-5} \mathrm{M}$ [DPro $^{2}$,D-Phe $\left.{ }^{7}, \mathrm{D}-\mathrm{Trp}^{9}\right] \mathrm{SP}$ and an identical analysis performed. With the addition of [D-Pro $\left.{ }^{2}, \mathrm{D}-\mathrm{Phe}^{7}, \mathrm{D}-\mathrm{Trp}^{9}\right] \mathrm{SP}$, the small positively staining peak in $A$ is no longer present in $B$.

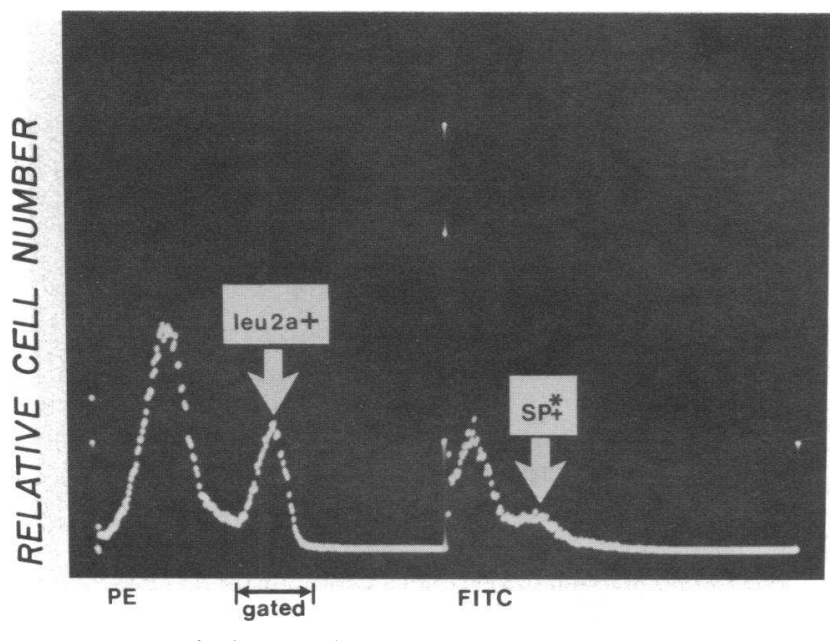

RELATIVE FLUORESCENCE INTENSITY

Figure 3. Two-color flow cytometric analysis of leu 2a-PE (suppressor-cytotoxic) expression and binding of SP-DTAF (SP*) to human blood T-lymphocytes. T-lymphocytes were stained sequentially with anti-leu 2a-PE and SP* and analyzed with a FACS IV with two parameters. The positively-staining anti-leu 2a-PE T-lymphocytes (left) were analyzed selectively (gated peak) and examined for the presence of $\mathrm{SP}^{*}$ reactivity. Within the leu 2a-positive peak, there are both nonreactive and SP*-reactive $(9.5 \%)$ (right) T-lymphocytes. The positively-staining anti-leu 2a-PE T-lymphocytes constituted $26 \pm 5 \%$ (mean \pm SD, $n=3$ ) of the total.

by leu $2 \mathrm{a}-\mathrm{PE}, 9.5 \pm 3.0 \%$ (mean \pm range, $n=3$ ) of the T-lymphocytes bound SP* (Fig. 3), while in the helper-inducer subset identified by leu 3a-PE, $18.0 \pm 5.0 \%$ (mean \pm range, $n$ $=3$ ) of the T-lymphocytes bound SP* (Fig. 4).

Characteristics of the binding of $\left[{ }^{3} \mathrm{H}\right] \mathrm{SP}$ to human blood $T$-lymphocytes. The time-course of association of $\left[{ }^{3} \mathrm{H}\right] \mathrm{SP}$ with purified $\mathrm{T}$-lymphocytes was assessed by incubating duplicate suspensions of $1 \times 10^{7} \mathrm{~T}$-lymphocytes with $10 \mathrm{nM}\left[{ }^{3} \mathrm{H}\right] \mathrm{SP}$ for 0.5-40 min at $4^{\circ} \mathrm{C}$. The specific binding of $\left[{ }^{3} \mathrm{H}\right] \mathrm{SP}$ by $\mathrm{T}$ lymphocytes increased with time and reached a plateau after 9-12 min (Fig. 5). The time-course of dissociation of specifically bound $\left[{ }^{3} \mathrm{H}\right] \mathrm{SP}$ from $\mathrm{T}$-lymphocytes was examined by incubating replicate suspensions of T-lymphocytes for $40 \mathrm{~min}$ at $4^{\circ} \mathrm{C}$ with $10 \mathrm{nM}\left[{ }^{3} \mathrm{H}\right] \mathrm{SP}$ to achieve saturation, washing with cold buffer to remove fluid phase $\left[{ }^{3} \mathrm{H}\right] \mathrm{SP}$, and resuspending in buffer with $10^{-4} \mathrm{M}(10,000$-fold excess) nonradioactive SP. Specifically bound $\left[{ }^{3} \mathrm{H}\right] \mathrm{SP}$ diminished rapidly with time, so that $\sim 50$ and $80 \%$ were dissociated after 5 and $30 \mathrm{~min}$, respectively (Fig. 5).

A representative Scatchard plot (Fig. 6) of the concentrationdependence of $\left[{ }^{3} \mathrm{H}\right] \mathrm{SP}$ binding to $\mathrm{T}$-lymphocytes reveals a linear relationship with a single dissociation constant $\left(K_{\mathrm{D}}\right)$ of $0.83 \times 10^{-7} \mathrm{M}$ and a mean of 4820 specific binding sites for SP/T-lymphocyte. The data from this and four other identical analyses of the binding of $\left[{ }^{3} \mathrm{H}\right] \mathrm{SP}$ to $\mathrm{T}$-lymphocytes from different normal subjects exhibit some donor-dependent vari- 


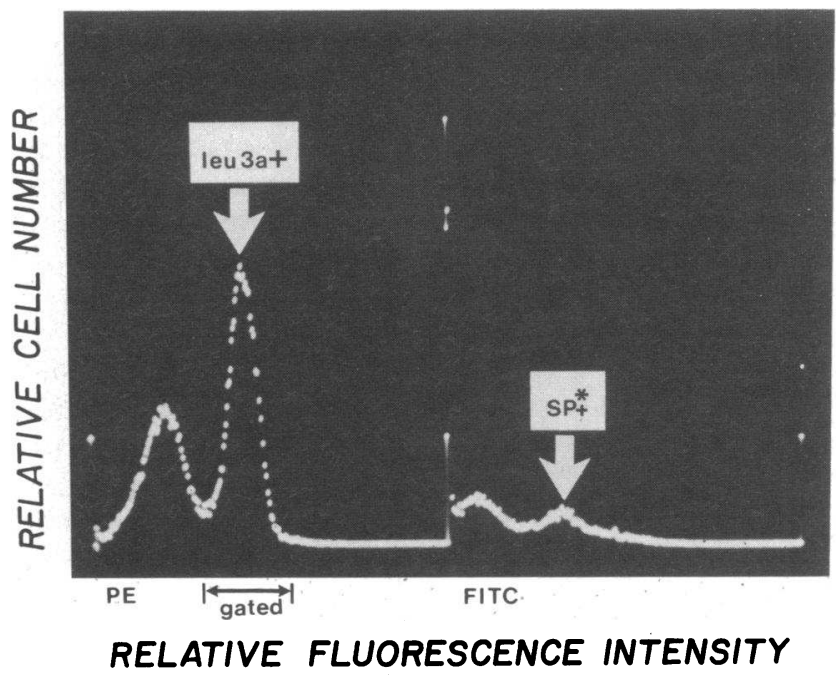

Figure 4. Two-color flow cytometric analysis of leu 3a-PE (helperinducer) expression and binding of SP-DTAF (SP*) to peripheral blood T-lymphocytes. T-lymphocytes were stained with anti-leu 3aPE and SP* and analyzed with a FACS IV as in Fig. 3. The positively staining anti-leu 3a-PE T-lymphocytes (left) were analyzed selectively (gated peak) and examined for the presence of SP* reactivity. Within the leu 3a-positive peak, there were both nonreactive and $\mathrm{SP}^{*}$ reactive (18\%) (right) T-lymphocytes. The positively staining anti-leu 3a-PE T-lymphocytes constituted $60 \pm 8 \%($ mean $\pm \mathrm{SD}, n=3)$ of the total.

ation (Table I). The mean $K_{\mathrm{D}} \pm \mathrm{SD}$ was $1.85 \pm 0.70 \times 10^{-7} \mathrm{M}$ and the mean density of binding sites for $\mathrm{SP} \pm \mathrm{SD}$ was $7035 \pm 2850 / T-l y m p h o c y t e$. The level of nonspecific binding of $\left[{ }^{3} \mathrm{H}\right] \mathrm{SP}$ after a 40 -min incubation at $4^{\circ} \mathrm{C}$ for five separate experiments was $35 \pm 15 \%$ (mean $\pm \mathrm{SD}$ ) of the total binding.

Structural determinants of the binding of SP to human $T$ lymphocytes. The peptide requirements for the binding of $\left[{ }^{3} \mathrm{H}\right] \mathrm{SP}$ to $\mathrm{T}$-lymphocytes was evaluated by examining the effects on binding of structurally distinct neuropeptides and substituents of SP (Fig. 5). The SP antagonist (19) [D-Pro ${ }^{2}$,D$\left.\mathrm{Phe}^{7}, \mathrm{D}-\mathrm{Trp}{ }^{9}\right] \mathrm{SP}$ competitively inhibited the binding of $\left[{ }^{3} \mathrm{H}\right] \mathrm{SP}$ to T-lymphocytes (Fig. 7) at concentrations known to suppress the stimulatory effects of SP on T-lymphocyte function (3). SP (4-11), which stimulates $\left[{ }^{3} \mathrm{H}\right]$ thymidine incorporation by T-lymphocytes (3), also competitively inhibited the binding of $\left[{ }^{3} \mathrm{H}\right] \mathrm{SP}$ to T-lymphocytes. Eledoisin, which has the same amino acids as SP at positions 2,7 , and 9-11, and substance $\mathrm{K}$ ( $\alpha$-neurokinin) (28), which has the same amino acids as SP at positions 3,7 , and 9-11, exhibited $\sim 10-20 \%$ of the potency of SP assessed at $20 \%$ displacement of binding of $\left[{ }^{3} \mathrm{H}\right] \mathrm{SP}$ and $10 \%$ and $0.1 \%$, respectively, of the potency of SP at $40 \%$ displacement (Fig. 7). In contrast, similar concentrations of the tetrapeptide SP (1-4) and of somatostatin failed to inhibit significantly the binding of $\left[{ }^{3} \mathrm{H}\right] \mathrm{SP}$; the concentration of somatostatin required for $50 \%$ inhibition of specific binding of $\left[{ }^{3} \mathrm{H}\right] \mathrm{SP}$ was 1,000 -fold greater than for SP.

Cellular specificity of the binding of $S P$. The binding of $\left[{ }^{3} \mathrm{H}\right] \mathrm{SP}$ by purified human blood B-lymphocytes, monocytes, PMN leukocytes, and platelets, and by cultured Jurkat, Hut 78, Molt-4, and differentiated U-937 and HL-60 cells was examined in two experiments (Table II). None of the non-Tlymphocytes demonstrated specific binding of $\left[{ }^{3} \mathrm{H}\right] \mathrm{SP}$ which exceeded $21 \%$ of the total binding. In contrast, the total binding of $\left[{ }^{3} \mathrm{H}\right] \mathrm{SP}$ by PHA-stimulated and unstimulated blood T-lymphocytes, which achieved a level similar to that of the cultured cells, consisted of over $60 \%$ specific binding as assessed by the addition of a 10,000-fold molar excess of unlabeled SP (Table II).

\section{Discussion}

The capacity of neuropeptides and other mediators to modify immune function specifically is dependent on recognition of the mediators by T-lymphocytes which express immunoregulatory activity. The application of two distinct techniques employing SP labeled by different methods demonstrated the

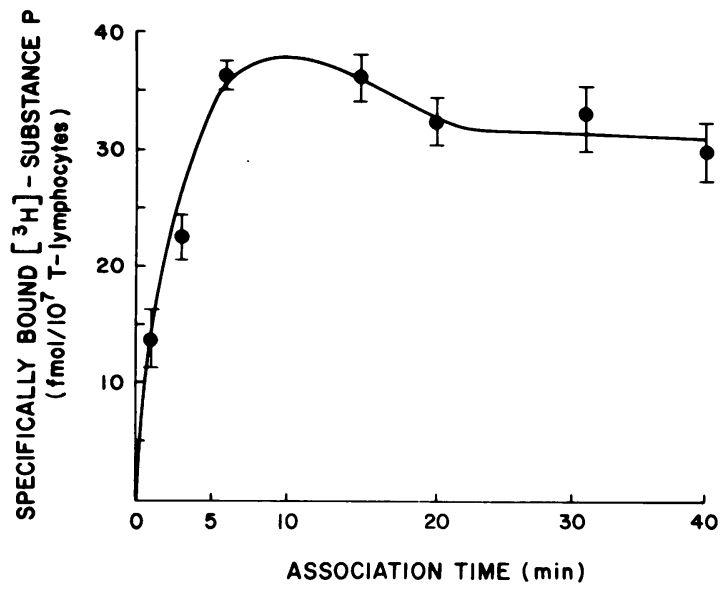

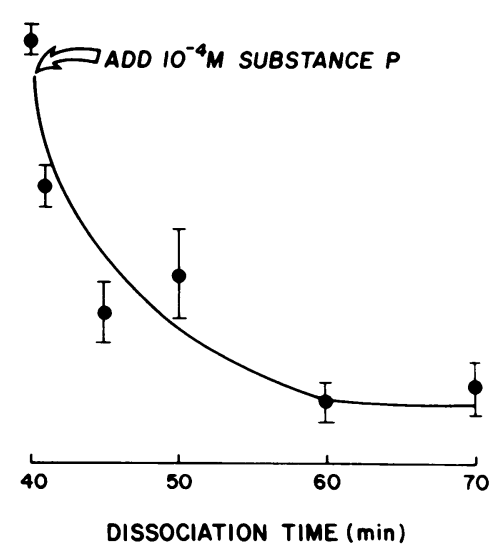

Figure 5. Time-course of specific binding of $\left[{ }^{3} \mathrm{H}\right] \mathrm{SP}$ to human T-lymphocytes. $\left[{ }^{3} \mathrm{H}\right] \mathrm{SP}$ was incubated with $1 \times 10^{7} \mathrm{~T}$. lymphocytes for different periods of time and the levels of specific binding were quantified. Each point and bracket represent the mean $\pm S D$ of three experiments done in duplicate. 


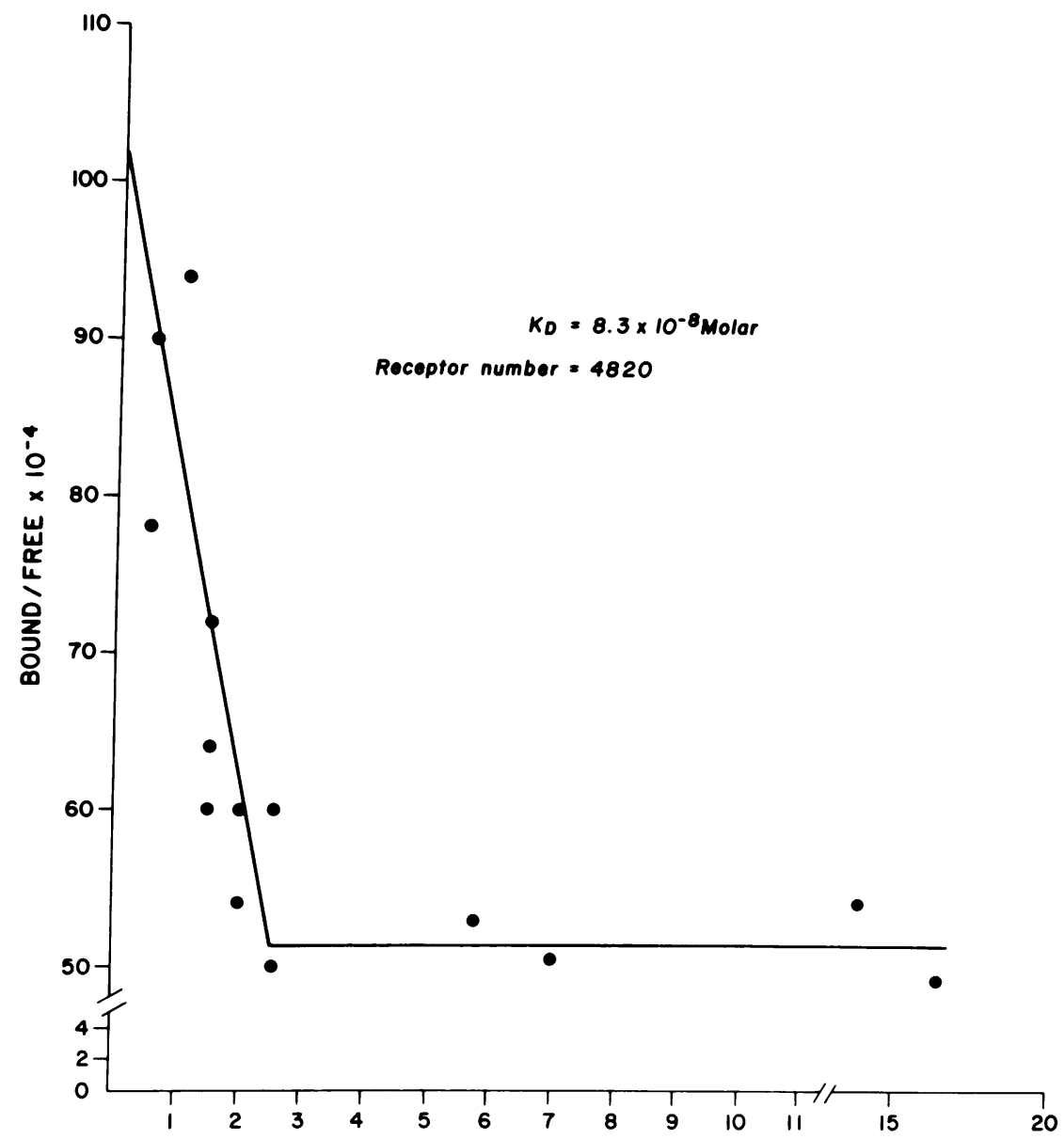

$\left[{ }^{3} \mathrm{H}\right]$ - SUBSTANCE P BOUND (MOLAR $\left.\times 10^{-10}\right) / 10^{7} \mathrm{~T}$-LYMPHOCYTES
Figure 6. Scatchard plot of the concentrationdependence of $\left[{ }^{3} \mathrm{H}\right] \mathrm{SP}$ binding to human T-lymphocytes. The data are based on total $\left[{ }^{3} \mathrm{H}\right] \mathrm{SP}$ bound by $1 \times 10^{7} \mathrm{~T}$-lymphocytes in the presence of increasing quantities of nonradioactive SP. Each point represents the mean of duplicate measurements for experiment number 1 (see Table I). The horizontal portion of the curve represents the amount of nonspecific binding of $\left[{ }^{3} \mathrm{H}\right] \mathrm{SP}$ to T-lymphocytes. specificity of the interaction of SP with human T-lymphocytes. A fluorescent derivative of SP, designated SP*, labeled $21 \pm 10 \%$ (mean $\pm \mathrm{SD}, n=6$ ) of human T-lymphocytes as assessed by flow cytometry (Fig. 1). The binding of $\left[{ }^{3} \mathrm{H}\right] \mathrm{SP}$ by similarly

Table I. Binding of $\left[{ }^{3} \mathrm{H}\right] \mathrm{SP}$ to Human Blood T-Lymphocytes

\begin{tabular}{lll}
\hline Experiment* & $\begin{array}{l}\text { Specific binding sites/ } \\
\text { T-lymphocyte }\end{array}$ & $\begin{array}{l}\mathrm{K}_{\mathbf{D}} \\
\left(\text { Molar } \times 10^{-7}\right) \ddagger\end{array}$ \\
\hline 1 & 4820 & 0.83 \\
2 & 7230 & 3.33 \\
3 & 9033 & 1.40 \\
4 & 10480 & 2.22 \\
5 & 3614 & 1.51 \\
Mean \pm SD & $7035 \pm 2850$ & $1.85 \pm 0.70 \times 10^{-7} \mathrm{M}$
\end{tabular}

* Experiments were done on blood T-lymphocytes from five different normal donors.

$¥$ The $K_{\mathrm{D}}$ and number of binding sites were determined by Scatchard analysis as described in the text. Each experiment was done in duplicate. purified human T-lymphocytes revealed a single class of receptors with a $K_{\mathrm{D}}$ of $1.85 \pm 0.70 \times 10^{-7} \mathrm{M}($ mean $\pm \mathrm{SD}, n=5)$ (Fig. 6, Table I). The binding of $\left[{ }^{3} \mathrm{H}\right] \mathrm{SP}$ to T-lymphocyte receptors achieved equilibrium rapidly and was reversed rapidly by the addition of excess nonradioactive SP (Fig. 5). The specificity of the interaction of SP with T-lymphocytes was confirmed by complete inhibition of both SP* fluorescent staining and $\left[{ }^{3} \mathrm{H}\right] \mathrm{SP}$ binding by [D-Pro $\left.{ }^{2}, \mathrm{D}-\mathrm{Phe}^{7}, \mathrm{D}-\mathrm{Trp}^{9}\right] \mathrm{SP}$ (Fig. 7) at concentrations which inhibit the effects of SP on Tlymphocyte function (3). The competitive inhibition of $\left[{ }^{3} \mathrm{H}\right] \mathrm{SP}$ binding by other peptides revealed that SP (4-11), which stimulates $\mathrm{T}$-lymphocyte proliferation with a concentration dependence similar to SP (3), displaced $\left[{ }^{3} \mathrm{H}\right] \mathrm{SP}$ at equimolar concentrations (Fig. 7). Two peptides of the tachykinin family, eledoisin and substance $K$, which share the same carboxyterminal tripeptide and two other amino acids with SP, also inhibit the binding of $\left[{ }^{3} \mathrm{H}\right] \mathrm{SP}$ to $\mathrm{T}$-lymphocytes at higher concentrations (Fig. 7). The structural requirements for binding of SP to T-lymphocytes suggest that the carboxy-terminal sequence-Gly-Leu-Met- $\mathrm{NH}_{2}$, which contributes to the stabilization of the structure of SP (29) and $\mathrm{Phe}^{7}$ but not the 


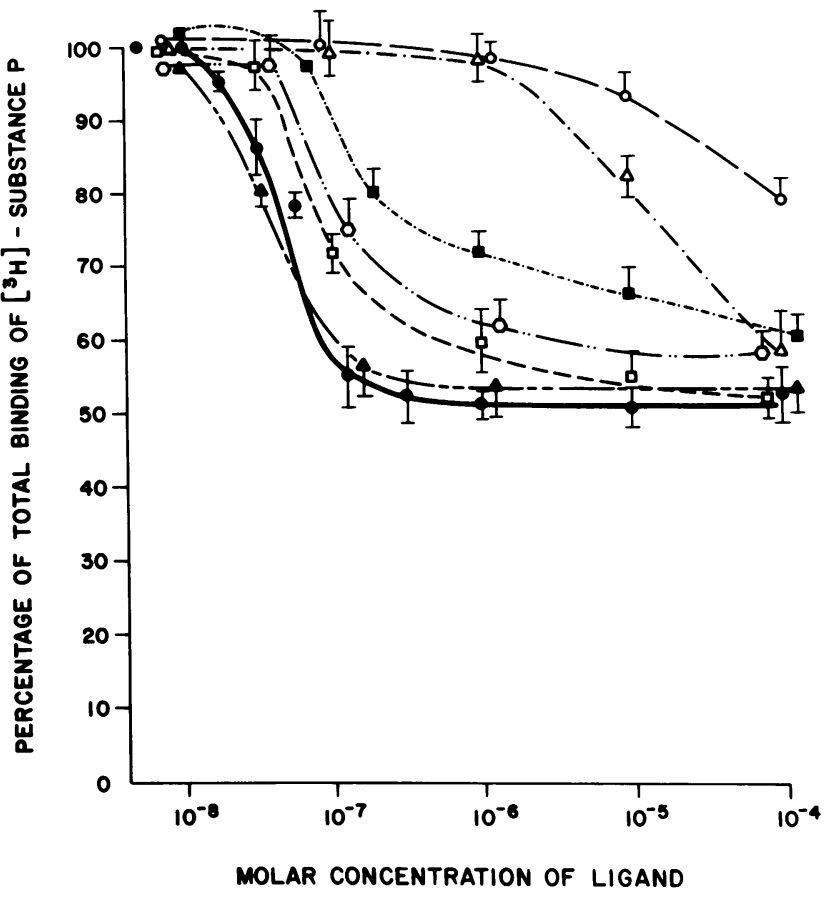

Figure 7. Structural determinants of binding of $\left[{ }^{3} \mathrm{H}\right] \mathrm{SP}$ to human $\mathrm{T}$ lymphocytes. Each point and bracket depicts the mean $\pm \mathrm{SD}$ of the percentage of total binding of $\left[{ }^{3} \mathrm{H}\right] \mathrm{SP}$ inhibited specifically by increasing concentrations of the nonradioactive peptides listed below, and $n$ equals the number of experiments. $\bullet, n=4$, SP Arg-Pro-Lys-ProGln-Gln-Phe-Phe-Gly-Leu-Met-NH ${ }_{2} ; \circ, n=2$, SP (1-4) Arg-Pro-LysPro; $\Delta, n=2$, SP (4-11) Pro-Gln-Gln-Phe-Phe-Gly-Leu-Met-NH ${ }_{2}$; o, $n=2$, eledoisin pGlu-Pro-Ser-Lys-Asp-Ala-Phe-Ile-Gly-Leu-Met$\mathrm{NH}_{2} ; n=2$, substance $\mathrm{K}$ His-Lys-Thr-Asp-Ser-Phe-Val-Gly-LeuMet-NH ${ }_{2} ; \Delta, n=2$, somatostatin (1-14) Ala-Gly-Cys-Lys-Asn-PhePhe-Trp-Lys-Thr-Phe-Thr-Ser-Cys; $\square, n=2$, [D-Pro ${ }^{2}, \mathrm{D}-\mathrm{Phe}^{7}, \mathrm{D}-$ Trp $\left.{ }^{9}\right]$ SP.

amino-terminal tetrapeptide, determine the affinity and specificity of the interaction.

Concurrent identification of helper-inducer and suppressorcytotoxic subsets of T-lymphocytes with PE-conjugated monoclonal antibodies to different leu antigens of the respective subsets permitted assignment of the SP-DTAF (SP*) fluorescence to T-lymphocytes in both subsets (Fig. 3 and 4). SP* was recognized by a mean of 18 and $9.5 \%$ of the helperinducer and suppressor-cytotoxic subsets of $T$-lymphocytes, respectively. The cellular specificity of the binding of SP was established by demonstrating a greater degree of specific binding of $\left[{ }^{3} \mathrm{H}\right] \mathrm{SP}$ to T-lymphocytes than to B-lymphocytes, monocytes, PMN leukocytes, platelets, and differentiated monocytes of the U-937 and HL-60 lines (Table II). SP, at concentrations of $10^{-11}-10^{-6} \mathrm{M}$ had no effect on the uptake of $\left[{ }^{3} \mathrm{H}\right]$ thymidine by the lymphoid cells Molt-4, Hut-78, and Jurkat in culture, and $\left[{ }^{3} \mathrm{H}\right] \mathrm{SP}$ failed to bind the cultured lymphoid cells.

The demonstration of labeling of only a mean of $21 \%$ of mixed T-lymphocytes with SP* permitted an estimation of the
Table II. Binding of $\left[{ }^{3} \mathrm{H}\right] S P$ to Different Types of Cells

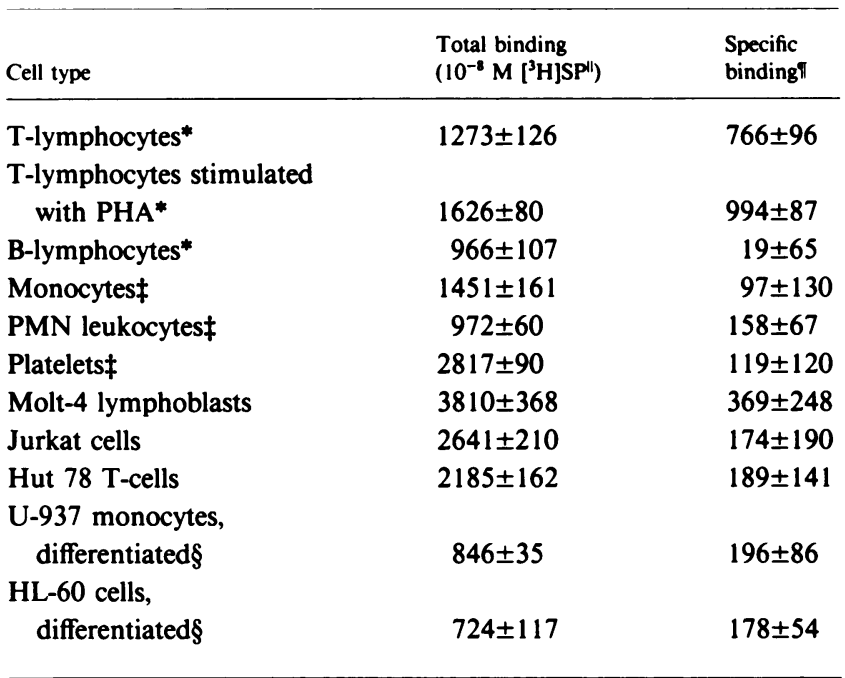

* Experiments utilized T- and B-lymphocytes isolated from five separate normal donors. T-lymphocytes were stimulated with $10 \mu \mathrm{g} / \mathrm{ml}$ of PHA for $48 \mathrm{~h}$.

‡ Experiments utilized PMN leukocytes, monocytes, and platelets from two separate normal donors.

$\S$ Two separate experiments were performed with cells stimulated to differentiate by $1,25(\mathrm{OH})_{2} \mathrm{D}_{3}$.

"Mean cpm bound $\pm \mathrm{SD} / 1 \times 10^{7}$ cells for duplicate measurements with cells from each donor, except in the case of platelets where 1 $\times 10^{9}$ cells in duplicate were used.

I Specific binding = total binding $\left(10^{-8} \mathrm{M}\left[{ }^{3} \mathrm{H}\right] \mathrm{SP}\right)$ minus nonspecific binding $\left(10^{-8} \mathrm{M}\left[{ }^{3} \mathrm{H}\right] \mathrm{SP}+10^{-4} \mathrm{M} \mathrm{SP}\right)$.

number of SP receptors. The Scatchard plot of the results of binding of $\left[{ }^{3} \mathrm{H}\right] \mathrm{SP}$ to $\mathrm{T}$-lymphocytes revealed a mean of 7035 SP receptors/T-lymphocyte, if all cells were assumed to bind SP (Fig. 6, Table I). Utilizing the flow cytometric data to define a subset of SP-reactive T-lymphocytes which amount to $21 \%$ of the total population led to an estimate of $\sim 35,000$ receptors/T-lymphocyte in the subset which recognized SP. The relevance of the binding data to the effects of SP on Tlymphocytes also was suggested by the similarity of the $K_{\mathrm{D}}$ to the concentration of $0.5 \times 10^{-7} \mathrm{M} \mathrm{SP}$ required to achieve $50 \%$ of the maximal stimulation of T-lymphocyte proliferation (3).

The selective interaction of SP with a quantitatively small subset of T-lymphocytes is reminiscent of the binding of $\mathrm{C} 3 \mathrm{a}$ peptides (21) and leukotriene $\mathrm{B}_{4}\left(\mathrm{LTB}_{4}\right)(30)$ to only $\sim 40$ and $11 \%$, respectively, of human blood T-lymphocytes. The distribution of SP*-reactive T-lymphocytes between the helperinducer (leu $3 a+)$ and suppressor-cytotoxic (leu $2 a+$ ) subsets resembles more that of $\mathrm{LTB}_{4}$-reactive lymphocytes within the same general subsets (30). Although $\mathrm{LTB}_{4}$ reacted with both subsets, a greater percentage of $\mathrm{LTB}_{4}$-reactive lymphocytes were suppressor-cytotoxic cells $(14 \%)$ than helper-inducer cells (8\%), with the net effect of $\mathrm{LTB}_{4}$ on proliferation being inhibition (23). In contrast, a greater percentage of SP-reactive 
T-lymphocytes were helper-inducer cells (18\%) compared with suppressor-cytotoxic cells (9\%), and the net effect of SP on proliferation is stimulation (3). However, the presence in the helper-inducer subset of suppressor-inducer T-lymphocytes emphasizes the difficulty of meaningfully explaining a functional outcome from the results of analyses with a limited number of monoclonal antibody reagents. The recognition of $\mathrm{C} 3 \mathrm{a}$ peptides and somatostatin by a minority of $\mathrm{T}$-lymphocytes also has substantial functional consequences, as manifested by significant suppression of proliferation $(1,21)$ and other activities (21). The in vitro findings suggest that the net effect on immunological responses of neuropeptides released from peripheral nerves may depend, in part, on the balance of the stimulatory effects of SP and the inhibitory effects of somatostatin.

\section{Acknowledgments}

This work was supported in part by National Institutes of Health grants 1PO1 AI19784 and 1RO1 HL31809, and by a grant from The Kroc Foundation.

\section{References}

1. Payan, D. G., C. A. Hess, and E. J. Goetzl. 1984. Inhibition of somatostatin of the proliferation of T-lymphocytes and Molt-4 lymphoblasts. Cell. Immunol. 84:433-438.

2. Hinterberger, W., C. Cerny, H. Kinast, H. Pointer, and K. H. Tragl. 1977. Somatostatin reduces the release of colony-stimulating activity (CSA) from PHA-activated mouse spleen lymphocytes. Experientia. 34:860-862.

3. Payan, D. G., D. R. Brewster, and E. J. Goetzl. 1983. Specific stimulation of human T-lymphocytes by substance P. J. Immunol. 131:1613-1615.

4. Gilman, S. C., J. M. Schwartz, R. J. Milner, F. E. Bloom, and J. D. Feldman. 1982. $\beta$-Endorphin enhances lymphocyte proliferative responses. Proc. Natl. Acad. Sci. USA. 79:4226-4230.

5. Johnson, H. M., E. M. Smith, B. A. Torres, and J. E. Blalock. 1982. Regulation of the in vitro antibody response by neuroendocrine hormones. Proc. Natl. Acad. Sci. USA. 79:4171-4174.

6. Mathews, P. M., C. J. Froelich, W. L. Sibbitt, and A. D. Bankhurst. 1983. Enhancement of natural cytotoxicity by $\beta$-endorphin. J. Immunol. 130:1658-1662.

7. Wybran, J., T. Appelboom, J.-P. Famaey, and A. Govaerts. 1979. Suggestive evidence for receptors for morphine and methionineenkephalin on normal human blood T-lymphocytes. J. Immunol. 123:1068-1070.

8. Beed, E. A., M. S. O'Dorisio, T. M. O'Dorisio, and T. S. Gaginella. 1983. Demonstration of a functional receptor for vasoactive intestinal peptide on Molt 4b T-lymphoblasts. Regul. Pept. 6:1-12.

9. Danek, A., M. S. O'Dorisio, T. M. O'Dorisio, and J. M. George. 1983. Specific binding sites for vasoactive intestinal poly-peptide on nonadherent peripheral blood lymphocytes. J. Immunol. 131:11731177.

10. Pernow, B. 1983. Substance P. Pharmacol. Rev. 35:85-141.

11. Hokfelt, T., J. O. Kellerth, G. Nilsson, and B. Pernow. 1975. Substance P: localization in the central nervous system and in some primary sensory neurons. Science (Wash. DC). 190:889-890.

12. Costa, M., J. B. Furness, R. Franco, I. Llewellyn-Smith, R.
Murphy, and A. M. Beardsley. 1982. Substance $P$ in nerve tissue in the gut. Ciba Found. Symp. 91:129-144.

13. Cuello, A. C., and I. Kanazawa. 1978. The distribution of substance $\mathbf{P}$ immunoreactive fibers in the rat central nervous system. J. Comp. Neurol. 178:129-156.

14. Johnson, A. R., and E. G. Erdos. 1973. Release of histamine from mast cells by vasoactive peptides. Proc. Soc. Exp. Biol. Med. 142:1252-1256.

15. Lembeck, F., J. Donnerer, and F. C. Colpaert. 1981. Increase of substance $\mathbf{P}$ in primary afferent nerves during chronic pain. Neuropeptides. 1:175-180.

16. Ljungdahl, A., T. Hokfelt, and G. Nilsson. 1978. Distribution of substance P-like immunoreactivity in the central nervous system of the rat. Neuroscience. 3:861-976.

17. Bar-Shavit, Z., R. Goldman, Y. Stabinsky, P. Gottlieb, M. Fridkin, V. I. Teichberg, and S. Blumberg. 1980. Enhancement of phagocytosis-a newly found activity of substance $\mathrm{P}$ residing in its $\mathrm{N}$ terminal tetrapeptide sequence. Biochem. Biophys. Res. Comm. 94:1445-1451

18. Lembeck, F., R. Gamse, and H. Juan. 1977. Substance $P$ and sensory nerve endings. In Substance P. U. S. von Euler and B. Pernow, editors. Raven Press, New York. 169-181.

19. Hartung, H. P., and K. V. Toyka. 1983. Activation of macrophages by Substance $P$ : induction of oxidative burst and thromboxane release. Eur. J. Pharm. 89:301-305.

20. Hanley, M. R. 1982. Substance $P$ antagonists. Trends Neurosci. 5:138-139.

21. Payan, D. G., D. E. Trentham, and E. J. Goetzl. 1982. Modulation of human lymphocyte function by $\mathrm{C} 3 \mathrm{a}$ and $\mathrm{C} 3 \mathrm{a}(70-77)$. J. Exp. Med. 156:756-765.

22. Valone, F. H., E. Coles, V. R. Reinhold, and E. J. Goetzl. 1982. Specific binding of phospholipid platelet-activating factor by human platelets. J. Immunol. 129:1637-1641.

23. Payan, D. G., and E. J. Goetzl. 1983. Specific suppression of human T-lymphocyte function by leukotriene $\mathrm{B}_{4}$. J. Immunol. 131:551553.

24. Bar-Shavit, Z., S. L. Teitelbaum, P. Reitsma, A. Hall, L. E. Pegg, J. Trial, and A. J. Kahn. 1983. Induction of monocytic differentiation and bone resorption by 1,25-dihydroxyvitamin $D_{3}$. Proc. Natl. Acad. Sci. USA. 80:5907-5911.

25. Mangelsdorf, D. J., H. P. Koeffler, C. A. Donaldson, J. W. Pike, and M. R. Hanssler. 1984. 1,25-Dihydroxyvitamin $D_{3}$-induced differentiation in human promyelocytic leukemia cell line (HL-60): receptor-mediated maturation to macrophage-like cells. J. Cell Biol. 98:391-398.

26. Watt, K. W. K., I. L. Brightman, and E. J. Goetzl. 1983. Isolation of two polypeptides comprising the neutrophil-immobilizing factor of human leukocytes. Immunology. 48:79-86.

27. Goldman, D. W., and E. J. Goetzl. 1982. Specific binding of leukotriene $B_{4}$ to receptors on human polymorphonuclear leukocytes. J. Immunol. 129:1600-1604.

28. Nawa, H., T. Hirose, H. Takashima, S. Inayama, and S. Nakanishi. 1983. Nucleotide sequences of cloned cDNAs for two types of bovine brain substance $P$ precursor. Nature (Lond.). 306:32-36.

29. Murakoshi, T., M. Yanagisawa, C. Kitada, M. Fujino, and M. Otsuka. 1983. The role of the $\mathrm{N}$-terminus in the active conformation of the substance P analogues. Eur. J. Pharm. 90:133-137.

30. Payan, D. G., A. Missirian-Bastian, and E. J. Goetzl. 1984. Human T-lymphocyte subset specificity of the regulatory effects of leukotriene $\mathrm{B}_{4}$. Proc. Natl. Acad. Sci. USA. 81:3501-3505. 